07

\title{
Исследование электрофизических свойств поверхности пористого GaP(111)
}

\author{
(C) С.А. Масалов ${ }^{1}$, А.В. Атращенко ${ }^{1,2}$, В.П. Улин ${ }^{1}$, Е.О. Попов ${ }^{1}$, \\ А.Г. Колосько ${ }^{1}$, С.В. Филиппов ${ }^{1}$ \\ ${ }^{1}$ Физико-технический институт им. А.Ф. Иоффре РАН, Санкт-Петербург \\ ${ }^{2}$ Университет ИТМО, Санкт-Петербург \\ E-mail: sergeym@mail.com
}

Поступило в Редакцию 17 июня 2016 г.

Проведены измерения локальных электрофизических свойств поверхности пористого GaP c использованием методики туннельной спектроскопии в сверхвысоком вакууме. Обнаружены две области поверхности с различными электрофизическими свойствами. Наблюдался эффект аномальной полевой фотоэмиссии, наиболее вероятной причиной которой является наличие нанокластеров $\mathrm{Ga}_{2} \mathrm{O}_{3}, \mathrm{GaP}$ и ассоциированных с ними поверхностных состояний акцепторного типа, обладающих высокой плотностью. Для получения интегральных характеристик полевой электронной эмиссии с поверхности образца использовалась компьютеризированная система регистрации с онлайнобработкой воль-тамперных характеристик.

В настоящее время все большее внимание исследователей привлекают пористые полупроводники, созданные на основе бинарных соединений $\mathrm{A}^{3} \mathrm{~B}^{5}$. Использование электрохимического травления монокристаллов позволяет изменять химический состав и кристаллографические характеристики их поверхности, создавать упорядоченные пористые структуры, образованные наноразмерными фрагментами исходного материала. Данная технология дает возможность варьировать величину запрещенной зоны получаемого материала [1], вводить искусственную оптическую анизотропию, а также эффективно влиять на электроннофононное взаимодействие [2] .

Наиболее сильные модификации свойств поверхности вызывает травление бинарных полупроводниковых соединений типа $\mathrm{A}^{3} \mathrm{~B}^{5}$, обладающих естественной поляризацией $(\mathrm{A}-\mathrm{B})$. В ходе электрохимического травления развивается процесс порообразования. При этом у формирующегося скелетного кристалла появляется развитая внутренняя 
поверхность, на которой удерживаются адсорбированные продукты электрохимического процесса. Существование такой поверхности определяет кардинальные отличия электрофизических свойств пористых кристаллов от свойств исходных монокристаллов.

Нами была разработана технология изготовления однородных нанопористых матриц на основе полупроводникового соединения $\mathrm{GaP}$ [3].

В задачи данной работы входило изучение локальных электрофизических и интегральных эмиссионных свойств поверхности таких матриц с использованием методики туннельной спектроскопии в сверхвысоком вакууме и методики регистрации вольт-амперных характеристик полевой эмиссии. Нанопористые матрицы для исследования были получены методом анодного электрохимического травления пластин сильнолегированного $n$-GaP с концентрацией носителей $3.7 \cdot 10^{18} \mathrm{~cm}^{-3}$. Исходная ориентация пластин (111)B, толщина $\sim 280 \mu \mathrm{m}$. Перед электрохимическим травлением подложки травились в горячем растворе $\mathrm{Br}_{2}$ в изобутиловом спирте (объемное соотношение $1: 10$ ). Травление проводилось в течение одной минуты с целью удаления слоя, нарушенного механической полировкой.

Электрохимическое анодное травление $\mathrm{GaP}$ производилось в $2.5 \mathrm{M}$ водном растворе КОН с использованием потенциостатического режима при напряжении $8 \mathrm{~V}$ в течение $240 \mathrm{~s}$. После электрохимического травления пористые образцы промывались в деионизованной воде и отжигались в высоком вакууме (не ниже чем $10^{-5} \mathrm{~Pa}$ ) при температуре $500^{\circ} \mathrm{C}$ в течение $40 \mathrm{~min}$, чтобы удалить из пор летучие продукты электрохимической реакции. Для удаления переходного слоя, где нанопоры имеют неустоявшуюся ориентацию, образец был обработан методом ионно-лучевого травления в аргоне. Толщина удаленного слоя составляла $\sim 2.5 \mu \mathrm{m}$.

Морфология поверхности и структура изготовленного образца были изучены с помощью сканирующего электронного микроскопа (JEOL JSM-7001F, Япония). Результаты измерений показали следующие параметры нанопористой матрицы: глубина пор $40 \mu \mathrm{m}$, диаметр пор 25-30 nm, шаг решетки 50-60 nm. Изображение поверхности нанопористой структуры представлено на рис. 1.

Для изучения особенностей локальных электрофизических свойств поверхности пористого $\mathrm{GaP}$ проводились спектроскопические измерения с использованием сверхвысоковакуумного туннельного микроскопа LS-SPM фирмы OMICRON. Напряжение смещения величиной от -10

Письма в ЖТФ, 2016, том 42, вып. 22 


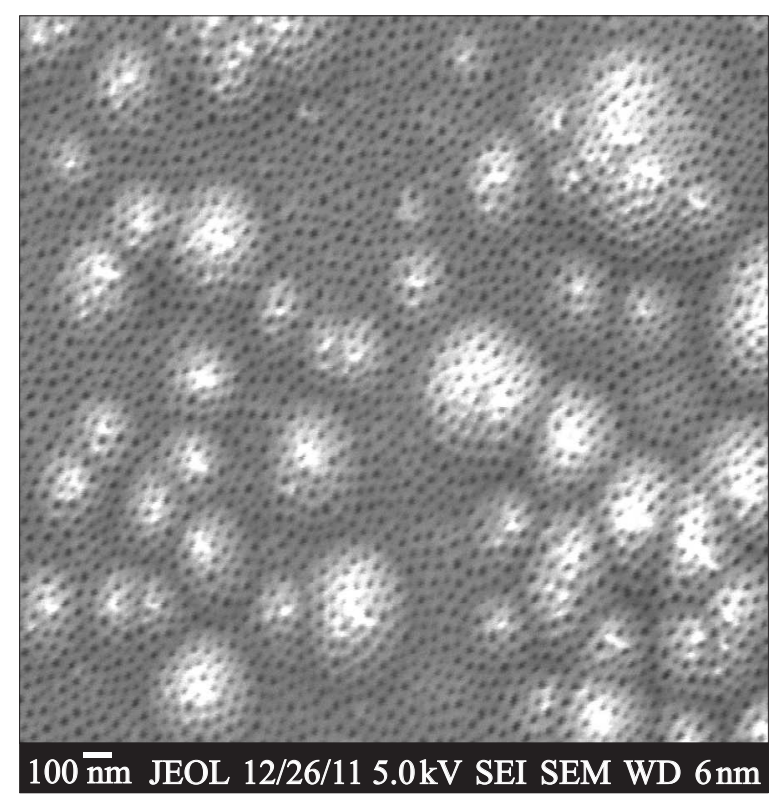

Рис. 1. Изображение участка поверхности GaP (111), полученное в сканирующем электронном микроскопе.

до $+10 \mathrm{~V}$ было приложено к металлическому СТМ-зонду. Исследуемый образец находился под потенциалом „земли“. Начальное напряжение смещения при измерении $\mathrm{BAX} U_{0}=-10 \mathrm{~V}$. В процессе измерений проводилось усреднение по 50 ВАХ. Дополнительно, в эксперименте образец освещался сфокусированным пучком зеленого лазера (длина волны $\lambda=532 \mathrm{~nm}$, плотность мощности $\left.P=5 \mathrm{~W} / \mathrm{cm}^{2}\right)$.

В результате исследований, проведенных в разных точках поверхности образца, были обнаружены два типа наноразмерных областей с различными электрофизическими свойствами, обозначенные нами как область $C$ и область $D$ (условно).

В области $C$ образец при отрицательном напряжении смещения проявлял себя как обычный широкозонный полупроводник. Полученная $\mathrm{BAX}$ (рис. 2,a) позволила оценить величину запрещенной зоны поверхности образца по началу процесса ударной ионизации

Письма в ЖТФ, 2016, том 42, вып. 22 


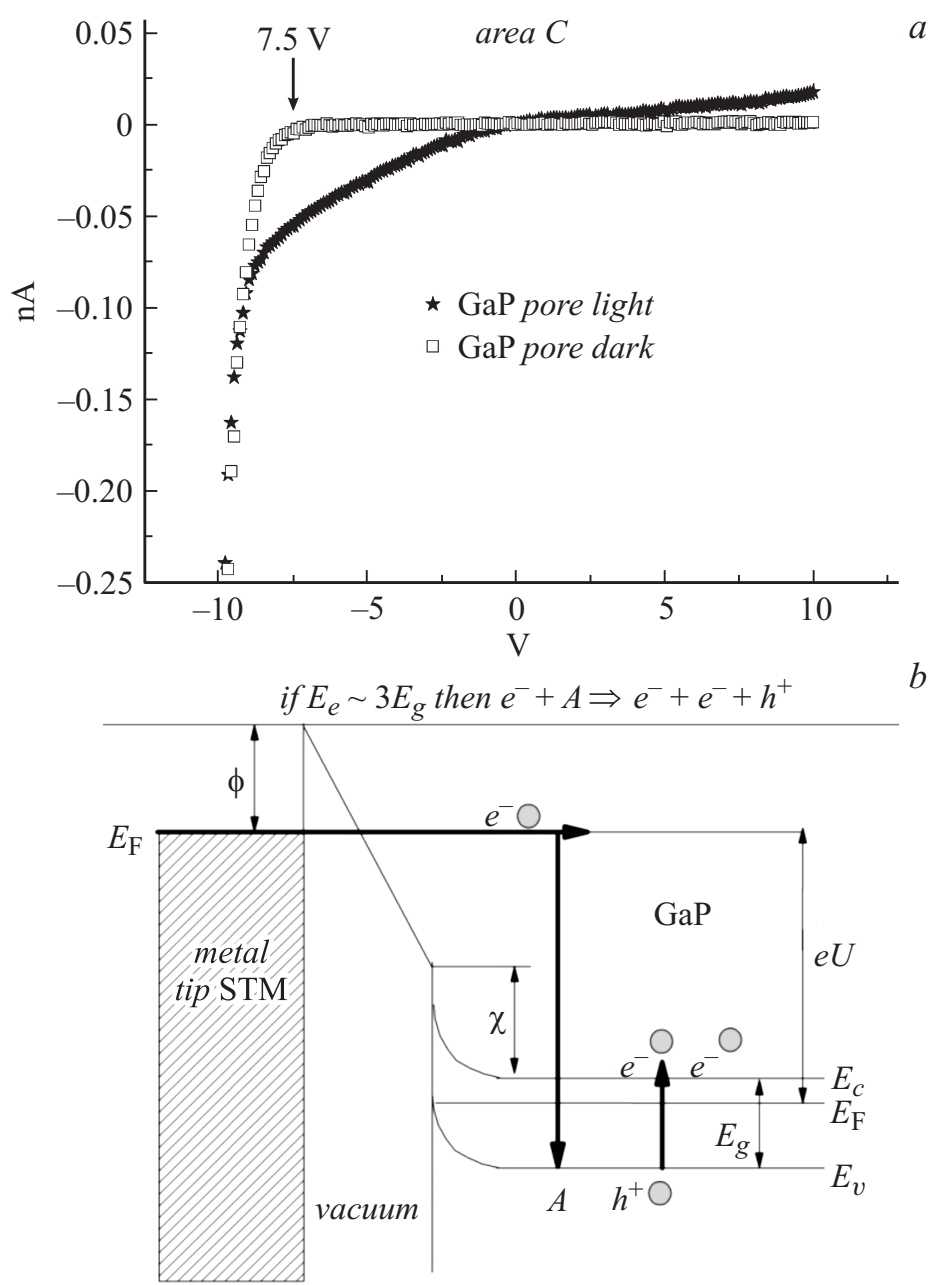

Рис. 2. Электрофизические свойства поверхности пористого $\mathrm{GaP}$ в области $C$ : $a-\mathrm{BAX}$ при освещении лазером $\lambda=532 \mathrm{~nm}$ и без него, начало процесса ударной ионизации при $e U=7.5 \mathrm{eV} ; b-$ энергетическая диаграмма контакта metal-vacuum-semiconductor. $\varphi$ - величина работы выхода металла, $\eta-$ электронное сродство полупроводника, $E_{C}-$ зона проводимости, $E_{V}-$ валентная зона, $E_{\mathrm{F}}-$ уровень Ферми, $U-$ напряжение смещения между электродами.

Письма в ЖТФ, 2016, том 42, вып. 22 
$E_{g} \sim 2.5 \mathrm{eV}$. Ударная ионизация приводит к созданию в приповерхностном слое свободных носителей заряда (электронно-дырочных пар) и обусловливает электрическую проводимость образца (рис. 2, b). Начало процесса ударной ионизации соответствует появлению ненулевого тока на отрицательной ветви ВАХ при облучении электронами с энергией $E \sim 3 E_{g}[4,5]$.

Полученная величина ширины запрещенной зоны несколько больше, чем запрещенная зона объемного $\mathrm{GaP}\left(E_{g}=2.26 \mathrm{eV}\right)$. Это можно объяснить как присутствием на поверхности пленки аморфного $\mathrm{Ga}_{2} \mathrm{O}_{3}$, так и модификацией зонной структуры $\mathrm{GaP}$ в наноструктурированном пористом кристалле.

При положительном напряжении смещения область $C$ проявляла себя как диэлектрик: ток в положительной ветви ВАХ отсутствовал (рис. 2,a). Это объясняется тем, что пористый слой $\mathrm{GaP}$ практически не содержит основных свободных носителей (электронов), поскольку они захвачены поверхностными состояниями, и поэтому пористый слой обладает низкой электрической проводимостью [3].

При освещении участка поверхности сфокусированным лазерным лучом в области $C$ наблюдалась небольшая по величине полевая фотоэлектронная эмиссия как при отрицательной, так и при положительной полярности напряжения смещения. Это обусловлено созданием свободных носителей в приповерхностном слое образца под действием электромагнитного излучения.

В другой характерной области поверхности образца (область $D$ ) при отсутствии лазерного освещения полевой эмиссионный ток не наблюдался. Включение же освещения привело к возникновению аномальной фотоэлектронной эмиссии: для напряжений смещения в диапазоне от -10 до $+10 \mathrm{~V}$ полевой эмиссионный ток всегда оставался положительным, т. е. даже при отрицательном напряжении смещения на СТМ-зонде электроны эмитировали с поверхности образца (рис. 3,a). Этот эффект можно объяснить появлением в результате освещения на поверхности отрицательного потенциала большой величины (не менее $-10 \mathrm{~V})$.

Возникновение такого потенциала можно представить при наличии в этой области полупроводниковой фазы с большой шириной запрещенной зоны, имеющей высокую плотность поверхностных состояний акцепторного типа. При сближении двух электродов (зонд-образец) возникающее сильное электрическое поле приводит к изгибу зон (рис. $3, b$ ) и созданию в приповерхностном слое двумерной потенциальной ямы

Письма в ЖТФ, 2016, том 42, вып. 22 


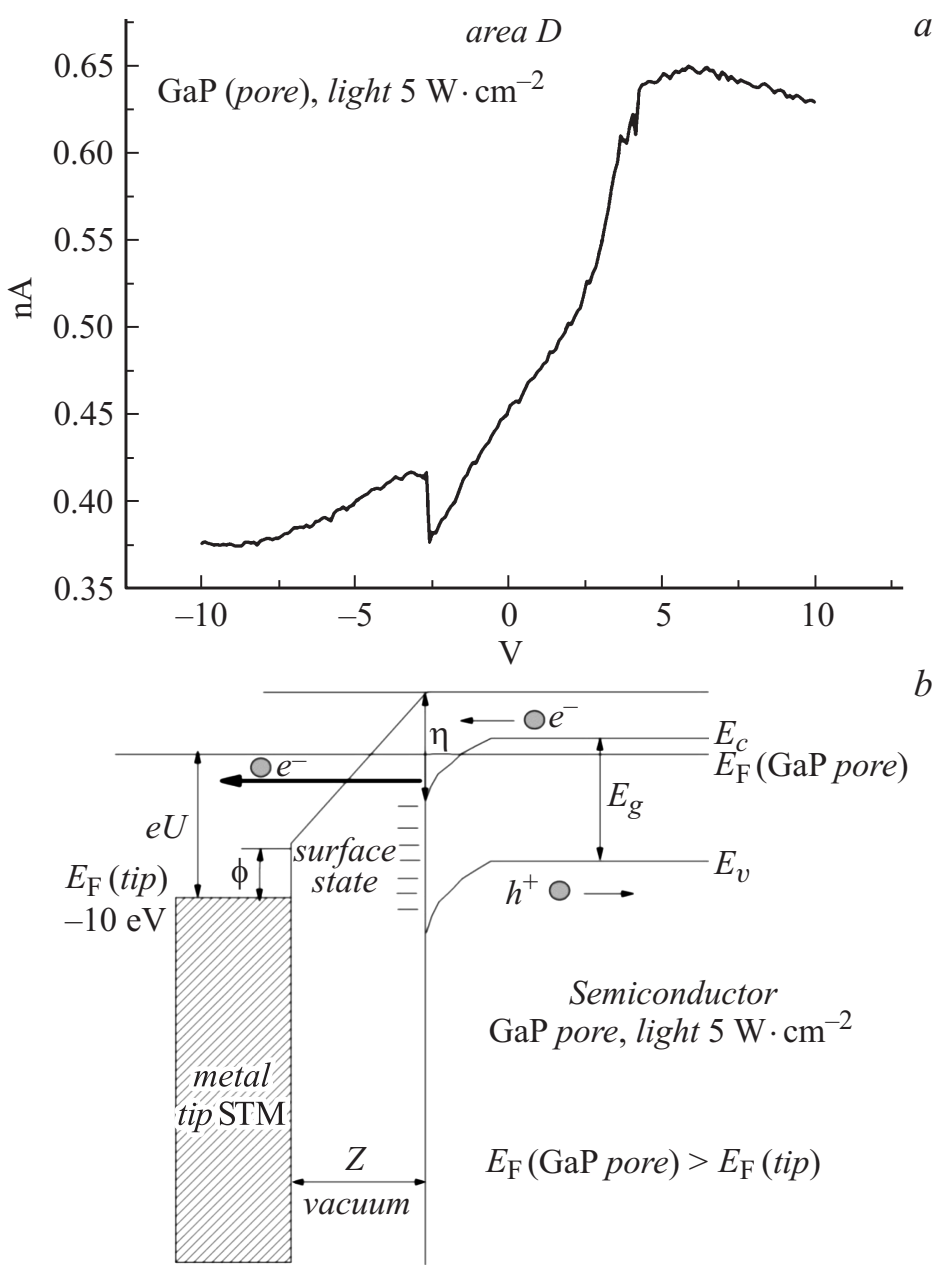

Рис. 3. Электрофизические свойства поверхности $\mathrm{GaP}$ в области $D: a-\mathrm{BAX}$ при освещении лазером $\lambda=532 \mathrm{~nm}$. Эмиссионный ток всегда положительный, т.е. электроны всегда эмитируют из образца. $b$ - энергетическая диаграмма контакта metal-vacuum-semiconductor, поясняющая возникновение аномальной полевой фотоэлктронной эмиссии. 
для электронов и потенциального барьера для дырок. Без воздействия электромагнитного излучения свободные носители отсутствуют и полевая эмиссия не наблюдается. При освещении этой области поверхности сфокусированным лазерным лучом происходит генерация и пространственное разделение свободных носителей. В результате создаются условия для туннелирования электронов из приповерхностной потенциальной ямы зоны проводимости образца, даже при отрицательном напряжении смещения на металлическом зонде.

Можно предположить, что область $C$, проявляющая себя как обычный широкозонный полупроводник, соответствует участкам кристалла, находящимся между порами. А аномальная фотоэлектронная эмиссия наблюдается непосредственно из области нанопор, область $D$.

Ранее нами были развиты представления о механизме электрохимического порообразования в полупроводниковых кристаллах $\mathrm{A}^{3} \mathrm{~B}^{5}$, происходящего под действием скачка потенциала на границе раздела полупроводник-электролит [6]. В ходе прорастания пор в объем кристалла большая часть первичных полимерных продуктов вытесняется в раствор, остающиеся же продукты переходят в устойчивые соединения $\mathrm{AX}_{3}, \mathrm{BX}_{3}$ с выделением мелкодисперсной фазы исходного соединения $\mathrm{AB}$.

В нашем случае использование щелочного электролита предполагает образование $\mathrm{Ga}(\mathrm{OH})_{3}$ и $\mathrm{H}_{3} \mathrm{PO}_{3}$. В результате отжига и термической диссоциации продуктов порообразования на стенках пор должны остаться нанокластеры $\mathrm{GaP}$ и $\mathrm{Ga}_{2} \mathrm{O}_{3}$. Благодаря эффектам размерного квантования, ширины запрещенных зон обеих мелкодисперсных полупроводниковых фаз должны существенно превышать их значения для объемных материалов. Наличие нанодисперсной широкозонной фазы позволяет удерживать в области пор большой отрицательный заряд.

Пористые полупроводники представляют интерес для создания планарных полевых источников электронов в связи с высокоразвитым рельефом поверхности, создающей большую плотность центров эмиссии. Поэтому кроме локальных исследований поверхности нанопористого GaP нами были проведены измерения его интегральных полевых эмиссионных характеристик.

В работе [7] использовался пористый $\mathrm{GaP}(100)$ для создания планарного полевого катода. После электрохимического травления была получена однородная поверхность с наноразмерными выступами. Измерения полевой электронной эмиссии показали удовлетворитель-

Письма в ЖТФ, 2016, том 42, вып. 22 

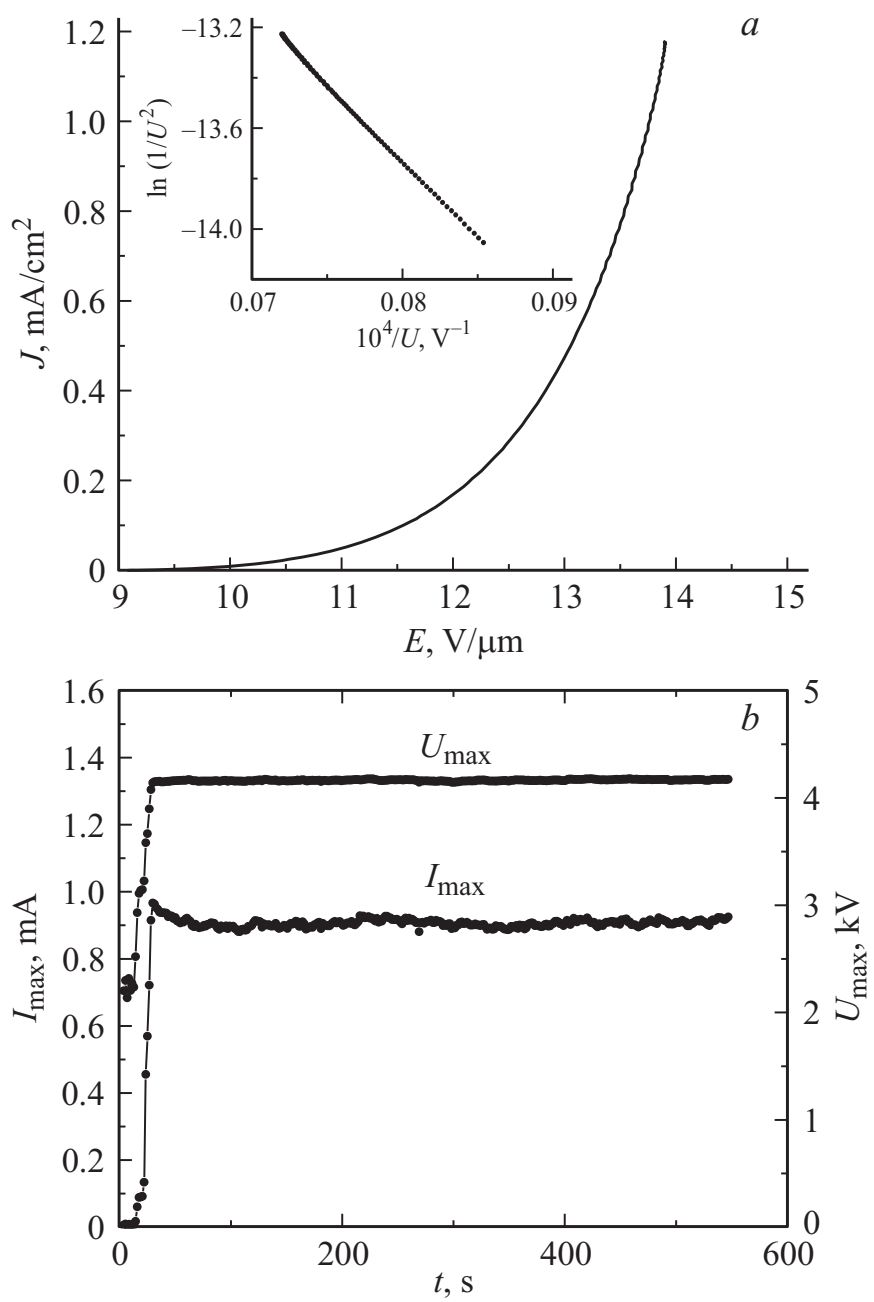

Рис. 4. Эмиссионные характеристики пористого $\mathrm{GaP}$ для площади образца диметром $5 \mathrm{~mm}: a-$ интегральная вольт-амперная характеристика. На врезке BAX, построенная в координатах Фаулера-Нордгейма, порог полевой электронной эмиссии $2.3 \mathrm{~V} / \mathrm{m} . b-$ стабильность во времени полевого эмиссионного тока, полученная при напряжении смещения $U \approx 4 \mathrm{kV}$.

Письма в ЖТФ, 2016, том 42, вып. 22 
ную стабильность эмиссионного тока и достаточно низкое пороговое напряжение.

Для определения интегральных полевых характеристик нанопористого GaP нами использовалась компьютеризированная система регистрации с онлайн-обработкой ВАХ [8]. Расстояние между катодом и анодом составляло $L \sim 300 \mu \mathrm{m}$. Измерялись интегральные $\mathrm{BAX}$ и временные зависимости полевого эмиссионного тока (рис. 4, $a, b$ ).

После „тренировки“ образца в переменном электрическом поле были получены ВАХ с достаточно низким пороговым полем $2.3 \mathrm{~V} / \mu \mathrm{m}$ и плотностью тока свыше $1 \mathrm{~mA} / \mathrm{cm}^{2}$ (рис. 4, $a$ ). При разности потенциалов $U \sim 4 \mathrm{kV}$ в течение достаточно длительного времени $(t \sim 600 \mathrm{~s})$ наблюдался стабильный полевой эмиссионный ток $I \sim 1 \mathrm{~mA}$ (рис. $4, b)$.

Существенное отличие интегральных полевых эмиссионных характеристик образца (рис. 4, $a$ ) от результатов СТМ-исследований, проведенных на нем ранее (рис. 2,a), можно объяснить диссоциацией $\mathrm{GaP}$ и формированием на поверхности капель $\mathrm{Ga}$ в результате полевой „тренировки“ образца. Механизм процессов, протекающих при такой „тренировке“, нуждается в дополнительных исследованиях.

В результате показано, что:

1) нанопористый $\mathrm{GaP}$ существенно неоднороден по своим электрофизическим свойствам;

2) пористый слой $\mathrm{GaP}$ становится проводящим только при генерации в нем неравновесных носителей;

3) существуют области с аномальной полевой фотоэмиссией;

4) в результате полевой „тренировки“ пористый $\mathrm{GaP}$ приобретает достаточно низкий порог полевой электронной эмиссии $(2.3 \mathrm{~V} / \mu \mathrm{m})$ и достаточно большой (1 mA) стабильный эмиссионный ток, следовательно, может использоваться как планарный полевой эмиссионный катод.

А.В. Атращенко благодарит фонд Программы президиума РАН и РФФИ (14-22-02064 офи-м) за частичную поддержку работы.

\section{Список литературы}

[1] Belogorokhov A.I., Karavanskii V.A., Obraztsov A.N., Timoshenko V.Yu. // JETP Lett. 1994. V. 60. P. 274.

[2] Tiginyanu I.M., Irmer G., Monecke J., Hartnagel H.L. // Phys. Rev. B. 1997. V. 55. P. 6739.

Письма в ЖТФ, 2016, том 42, вып. 22 
[3] Atrashchenko A., Arlauskas A., Adomavicius R. et al. // Appl. Phys. Lett. 2014. V. 105. N 20. P. 191905.

[4] Mac-Kay K. // Phys. Rev. 1951. V. 84. P. 829.

[5] Богданкевич О.В., Дарзнек С.А., Елисеев П.Г. // Полупроводниковые лазеры. М.: Наука, 1976. С. 209.

[6] Улин В.П., Конников С.Г. // ФТП. 2007. Т. 41. В. 7. С. 854.

[7] Ichizli V., Hartnagel H.L., Mimura H. et al.// Appl. Phys. Lett. 2001. V. 79. N 24. P. 4016.

[8] Колосько А.Г., Ершов М.В., Филиппов С.В., Попов Е.О. // Письма в ЖТФ. 2013. T. 39. B. 10. C. 72 . 